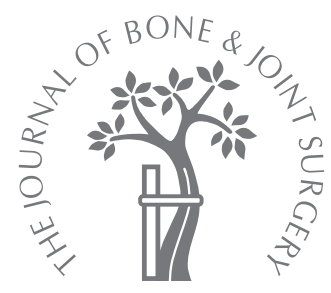

CHILDREN'S ORTHOPAEDICS

\title{
Combined treatment of congenital pseudarthrosis of the tibia, including recombinant human bone morphogenetic protein-2
}

\author{
A CASE SERIES
}
A. S. Spiro,
K. Babin,
S. Lipovac,
P. Stenger,
K. Mladenov,
M. Rupprecht,
J. M. Rueger,
R. Stuecker

From the Department of Pediatric

Orthopaedic Surgery,

Children's Hospital,

Hamburg, Germany

A. S. Spiro, MD, Orthopaedic Surgeon

M. Rupprecht, MD,

Orthopaedic Surgeon

J. M. Rueger, MD,

Orthopaedic Surgeon

Department of Trauma, Hand

and Reconstructive Surgery

University Medical Center,

Hamburg-Eppendorf,

Martinistrasse 52, 20246

Hamburg, Germany.

K. Babin, MD, Orthopaedic Surgeon

S. Lipovac, MD, Orthopaedic

Surgeon

P. Stenger, MD, Orthopaedic

Surgeon

K. Mladenov, MD,

Orthopaedic Surgeon

R. Stuecker, MD, Orthopaedic

Surgeon

Department of Pediatric

Orthopaedic Surgery

Children's Hospital, Hamburg-

Altona, Bleickenalle 38, 22763

Hamburg, Germany.

Correspondence should be sent to $\operatorname{Dr}$ A. S. Spiro; e-mail: aspiro@uke.uni-hamburg.de

(C)2011 British Editorial Society of Bone and Joint Surgery doi:10.1302/0301-620X.93B5. $25938 \$ 2.00$

$J$ Bone Joint Surg [Br] 2011;93-B:695-9.

Received 23 September 2010;

Accepted after revision 18

January 2011

The use of recombinant human bone morphogenetic protein-2 (rhBMP-2) for the treatment of congenital pseudarthrosis of the tibia has been investigated in only one previous study, with promising results. The aim of this study was to determine whether rhBMP-2 might improve the outcome of this disorder. We reviewed the medical records of five patients with a mean age of 7.4 years (2.3 to 21) with congenital pseudarthrosis of the tibia who had been treated with rhBMP-2 and intramedullary rodding. Ilizarov external fixation was also used in four of these patients. Radiological union of the pseudarthrosis was evident in all of them at a mean of 3.5 months (3.2 to 4 ) post-operatively. The llizarov device was removed after a mean of 4.2 months (3.0 to 5.3). These results indicate that treatment of congenital pseudarthrosis of the tibia using rhBMP-2 in combination with intramedullary stabilisation and llizarov external fixation may improve the initial rate of union and reduce the time to union.

Further studies with more patients and longer follow-up are necessary to determine whether this surgial procedure may significantly enhance the outcome of congenital pseudarthrosis of the tibia, considering the refracture rate (two of five patients) in this small case series.

The treatment of congenital pseudarthrosis of the tibia (CPT) often requires many operations including resection of the pseudarthrosis, bridging or closing the defect and stable fixation. ${ }^{1}$ External fixation, intramedullary stabilisation and free vascularised fibular grafts are among the most frequently used methods of treatment, with varying degrees of success. ${ }^{2-9}$

In recent years, our knowledge of bone repair and regeneration at both the cellular and the molecular level has improved greatly. Bone morphogenetic proteins (BMPs) have been shown to play an essential role in bone formation and fracture healing by inducing mesenchymal cell differentiation, proliferation and maturation into osteoblasts. ${ }^{10-13}$ The biological activity of recombinant human bone morphogenetic protein-2 (rhBMP-2) and rhBMP-7 to improve the healing of bone defects is well documented in animal studies. ${ }^{11,14}$ Also, since the United States Food and Drug Administration approved their clinical use in specific conditions, many clinical studies have demonstrated their safety in the treatment of tibial nonunions and open tibial fractures. ${ }^{15,16}$
There are only two studies and a few case reports regarding the use of rhBMPs in the treatment of CPT, ${ }^{17-21}$ and the aim of this study was to determine whether rhBMP-2 would improve the rate of union and the time to union in patients with CPT.

\section{Patients and Methods}

We reviewed the medical records of five patients with CPT whom we treated between 2006 and 2009. All had been treated with rhBMP-2 and intramedullary fixation. Ilizarov external fixation was also used in four of these patients. Their mean age at operation was 7.4 years $(2.3$ to 21$)$. Three patients had neurofibromatosis; the other two had no associated disorders. Four had a Crawford's classification $^{22}$ type IV pseudarthrosis with a pathological fracture, and one (case 3) had a type II lesion (Table I).

Three patients had conservative management of the pseudarthrosis before surgery was performed with the use of rhBMP-2 at our institution. Operative treatment had failed in two patients. One of these (case 1) had two 
Table I. Pre-operative data

\begin{tabular}{|c|c|c|c|c|c|c|}
\hline Patient & Side & $\begin{array}{l}\text { Age } \\
\text { (yrs) }\end{array}$ & Gender & Type of pseudarthrosis ${ }^{*}$ & $\begin{array}{l}\text { Previous surgical } \\
\text { treatment }\end{array}$ & Neurofibromatosis \\
\hline 1 & $\mathrm{R}$ & 3.5 & Male & IV & $\begin{array}{l}\text { Intramedullary rod } \\
\text { Ilizarov device } \\
\text { Bone graft }\end{array}$ & Yes \\
\hline 2 & $\mathrm{R}$ & 2.3 & Female & IV & None & No \\
\hline 3 & $\mathrm{R}$ & 5.1 & Female & II & None & Yes \\
\hline 4 & $\mathrm{R}$ & 21.0 & Female & IV & $\begin{array}{l}\text { Intramedullary rod } \\
\text { Ilizarov device } \\
\text { Bone graft }\end{array}$ & Yes \\
\hline 5 & $\mathrm{~L}$ & 5.0 & Female & IV & None & No \\
\hline
\end{tabular}

Table II. Surgical procedure

\begin{tabular}{lllll}
\hline Patient & Surgical procedure & \multicolumn{1}{c}{$\begin{array}{l}\text { Fibular osteotomy or } \\
\text { partial resection }\end{array}$} & $\begin{array}{l}\text { Transfixation of } \\
\text { ankle }\end{array}$ & $\begin{array}{l}\text { rhBMP-2 dose } \\
\text { (mg) }\end{array}$ \\
\hline 1 & $\begin{array}{l}\text { Resection of tibial }(3 \mathrm{~cm}) \text { and fibular pseudarthrosis } \\
\text { Bailey-Dubow nail; Ilizarov device }\end{array}$ & Partial resection & No \\
2 & $\begin{array}{l}\text { Resection of tibial pseudarthrosis }(2.5 \mathrm{~cm}) \\
\text { Bailey-Dubow nail; Ilizarov device } \\
\text { Resection of periosteum around the pseudarthrosis } \\
\text { site; wedge resection proximal and distal to the tibial } \\
\text { pseudarthrosis; Bailey-Dubow nail } \\
\text { Resection of tibial pseudarthrosis }(5 \mathrm{~cm}) \\
\text { Steinmann pin; Ilizarov device } \\
\text { Resection of tibial pseudarthrosis }(4 \mathrm{~cm}) \\
\text { Steinmann pin; Ilizarov device }\end{array}$ & Osteotomy & No & 12 \\
4 & Partial resection & Yes & 12 \\
5 & Partial resection & Yes & 12 \\
\hline
\end{tabular}

previous operations and the other (case 4) had undergone 28 previous surgical procedures, including resection of the pseudarthrosis, intramedullary fixation, bone grafting and Ilizarov fixation. She was 21 years old when rhBMP-2 was used to treat her at our hospital. Four patients were able to walk with a knee-ankle-foot orthosis pre-operatively, and one (case 3) required a femoral orthosis. Informed consent for the use of rhBMP-2 was obtained from the parents of each patient.

Operative technique. With the patient supine on a radiolucent table and using a tourniquet, the pseudarthrosis was exposed through a longitudinal anterior incision. The soft tissue within the pseudarthrosis was excised and the bone ends were resected back to healthy-appearing bone. The mean length of resected bone was $3.6 \mathrm{~cm}$ (2.5 to 5.0). Care was taken to remove the whole periosteum around the pseudarthrosis. In order to allow complete apposition of the ends of the tibia, a fibular osteotomy or a partial resection was undertaken through a separate lateral incision. The medullary canals of the proximal and distal tibial fragments were drilled with increasingly larger drill bits and intramedullary fixation was achieved by retrograde transfixation of the ankle with either a rod through the heel (Steinmann pin; cases 4 and 5) or by using the male part of a telescopic Bailey-Dubow nail (cases 1 to 3), stabilising only the tibia without transfixing the ankle joint. The type of fixation was at the discretion of the surgeon. The four patients with type-IV pseudarthrosis were also treated by the Ilizarov technique, whereby the tibia was shortened to appose of the bone ends and static compression applied across the resected pseudarthrosis. In three patients (cases 1,2 and 4) who had distal lesions and required further stabilisation, the foot was also included. In one patient (case 5) with a limb-length discrepancy of $4 \mathrm{~cm}$, the pseudarthrosis site was resected and a proximal corticotomy performed for segmental bone transport.

At the end of the operation the wound was irrigated and particular attention paid to haemostasis, before application of the BMP-2 composite (InductOs; Medtronic Sofamor Danek, Munster, Germany). According to the manufacturer's directions, this was prepared with collagen sponges which were placed around the pseudarthrosis. The subcutaneous tissue was carefully closed over the sponges using interrupted sutures.

One patient (case 3) had a different operation. She had type II pseudarthrosis with anterior bowing of $50^{\circ}$ and a sclerotic medullary canal without a pseudarthrosis. Preoperative MRI showed no neurofibromata within the bone. After resection of the periosteum around the apex, wedge resections were performed proximal and distal to the apical sclerotic bone to correct the bowing. The sclerotic medullary canal was reamed to accept an intramedullary nail. The proximal and distal tibial fragments were also drilled, and a Bailey-Dubow nail was inserted. The BMP-2-saturated collagen sponges were then placed around the apex and both osteotomies. The ankle joint was not transfixed and an Ilizarov device was not used. Table II summarises the surgical procedures for each patient. 


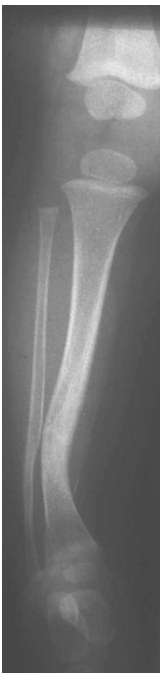

Fig. 1a

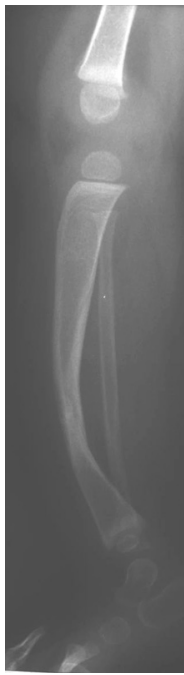

Fig. 1b

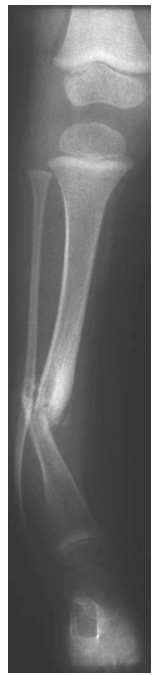

Fig. 1c

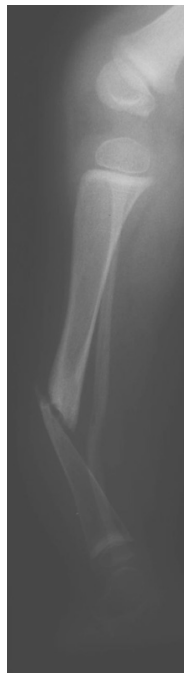

Fig. 1d

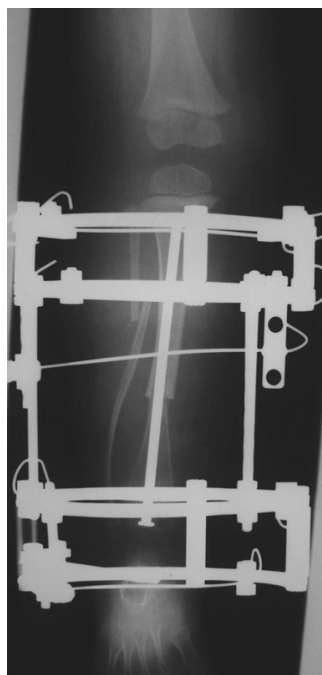

Fig. 1e

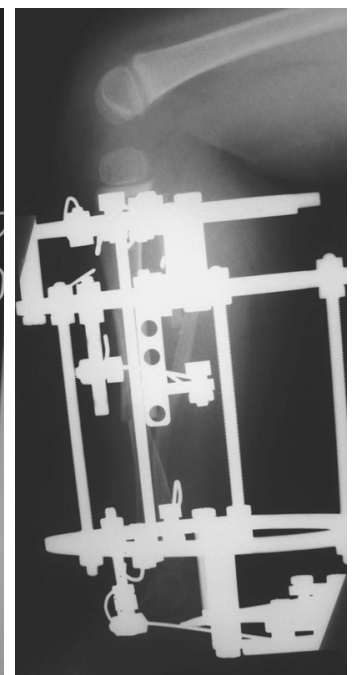

Fig. 1f

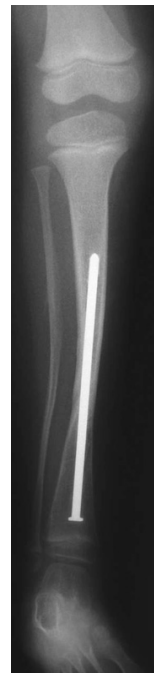

Fig. 1g

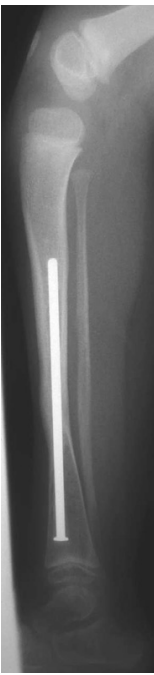

Fig. 1h

Figures $1 \mathrm{a}$ and $1 \mathrm{~b}$ - anteroposterior (a) and lateral (b) radiographs of an 11-month-old girl (case 2) with congenital pseudarthrosis of the right tibia. The radiographs show a varus deformity and anterior bowing of the tibia, as well as a sclerotic medullary canal at the pseudarthrosis site. Figures $1 \mathrm{c}$ and $1 \mathrm{~d}$ - anteroposterior (c) and lateral (d) radiographs of the same patient 14 months later demonstrate persistent nonunion after a pathological fracture occurred at the pseudarthrosis site. The patient therefore underwent surgical treatment at the age of 2.3 years. Figures $1 \mathrm{e}$ and $1 \mathrm{f}-$ anteroposterior (e) and lateral $(f)$ radiographs two days after resection of the tibial pseudarthrosis, intramedullary fixation with a Bailey-Dubow nail, llizarov external fixation, rhBMP-2 administration, and fibular osteotomy. The pseudarthrosis showed radiological evidence of healing 3.2 months after surgical intervention. Figures $1 \mathrm{~g}$ and $1 \mathrm{~h}$ - anteroposterior $(\mathrm{g})$ and lateral $(\mathrm{h})$ radiographs 19 months after surgical intervention, showing sustained radiological healing.

Clinical and radiological examinations were performed at approximately six-week intervals until six months postoperatively, and thereafter every six to 12 months. Radiological healing was defined as evidence of bridging across the tibial cortical defect at the pseudarthrosis.

\section{Results}

There were no complications during surgery, but a $2 \mathrm{~cm} \times$ $2 \mathrm{~cm}$ skin defect remained in one patient. This was covered with Epigard (Biovision GmbH, Ilmenau, Germany), which was removed after 11 days, with complete healing of the defect. Early post-operative complications included a pinsite infection in case 1 , necessitating pin removal after two months and a compartment syndrome (case 2) without muscle necrosis two days post-operatively. This patient underwent radical fasciotomies and two further wound revisions. The skin was closed four weeks after the original operation and there were no further complications or functional restrictions. She was allowed full weight-bearing five weeks after the primary operation, whereas the other three patients who had external fixation were mobilised fully weight-bearing immediately. The patient without external fixation was managed in a non-weight-bearing long-leg cast for six weeks and then with a full-weight-bearing femoral orthosis.

Radiological union of the pseudarthrosis was evident in all four patients who underwent resection of the pseudarthrosis, intramedullary nailing, Ilizarov fixation and rhBMP-2 administration at a mean of 3.5 months (3.2 to 4$)$ postoperatively (Fig. 1). The Ilizarov devices were removed after a mean of 4.2 months ( 3.0 to 5.3) and the patients were managed in a full-weight-bearing orthosis continuously. In one patient the Steinmann pin was removed to allow ankle mobility (case 5). In the others the intramedullary nail was left in place for additional stabilisation.

Of the four patients with radiological evidence of union after the initial procedure, two maintained union at a mean of 31.5 months (28 to 35 ). The other two (cases 1 and 5) sustained re-fracture at the initial pseudarthrosis site after a fall. One of these (case 1) suffered the fracture 21 months after the primary operation, and following unsuccessful conservative management over ten months he underwent exchange of the Bailey-Dubow nail, resection of the pseudarthrosis, Ilizarov external fixation and repeat BMP-2. The pseudarthrosis healed 5.4 months post-operatively, when the Ilizarov device was removed. At the most recent followup, 17 months post-operatively, there was still evidence of union and he could walk with a full-contact knee-anklefoot orthosis.

The second patient (case 5) sustained a re-fracture 6.4 months post-operatively. The Ilizarov device and the Steinmann pin had been removed six weeks before the accident, two days after which she underwent closed reduction and intramedullary stabilisation using two Prévot nails. Post-operatively, she was managed in a full-weight-bearing above-knee cast for eight weeks, and then with a femoral orthosis. At the latest follow-up, 3.6 months after surgery, radiographs showed increased callus formation, but there remained no evidence of bridging across the whole transverse cortical defect. 
Table III. Radiological follow-up data

\begin{tabular}{llll}
\hline Patient & Primary radiological endpoint & $\begin{array}{l}\text { Time to primary radiological } \\
\text { endpoint (mths) }\end{array}$ & $\begin{array}{l}\text { Result at latest } \\
\text { follow-up }\end{array}$ \\
\hline 1 & Union & 4.0 & Union \\
2 & Union & 3.2 & Union \\
3 & ${\mathrm{n} / \mathrm{a}^{*}}$ & $\mathrm{n} / \mathrm{a}$ & $\mathrm{n} / \mathrm{a}$ \\
4 & 3.0 & Union \\
5 & Union & 3.9 & Fracture $^{\dagger}$ \\
\hline * n/a, not applicable (no resection of pseudarthrosis was performed in this patient) \\
† increased consolidation of ipsilateral tibial fracture
\end{tabular}

Table IV. Clinical follow-up data

\begin{tabular}{|c|c|c|c|c|c|}
\hline Patient & $\begin{array}{l}\text { Duration of } \\
\text { follow-up (mths) }\end{array}$ & Activities and brace & $\begin{array}{l}\text { Range of movement } \\
\text { knee/ankle }\end{array}$ & Complications & Additional surgery \\
\hline 1 & 48 & $\begin{array}{l}\text { Active, no restrictions } \\
\text { Knee-ankle-foot orthosis }\end{array}$ & Full $/ 35^{\circ}$ & $\begin{array}{l}\text { Pin tract infection } \\
\text { Tibial fracture through the } \\
\text { healed pseudarthrosis } 21 \\
\text { months after surgery }\end{array}$ & $\begin{array}{l}\text { Exchange of intramedullary nail, } \\
\text { resection of pseudarthrosis, } \\
\text { Ilizarov external fixation and } \\
\text { repeat rhBMP-2 administration }\end{array}$ \\
\hline 2 & 35 & $\begin{array}{l}\text { Active, no restrictions } \\
\text { Knee-ankle-foot orthosis }\end{array}$ & Full/full & Compartment syndrome & $\begin{array}{l}\text { Fasciotomy and two further } \\
\text { wound revisions }\end{array}$ \\
\hline 3 & 34 & $\begin{array}{l}\text { Active, no restrictions } \\
\text { Knee-ankle-foot orthosis }\end{array}$ & Full/full & None & None \\
\hline 4 & 28 & $\begin{array}{l}\text { Active, no restrictions } \\
\text { Knee-ankle-foot orthosis }\end{array}$ & Full/ $/ 0^{\circ}$ & None & None \\
\hline 5 & 10 & $\begin{array}{l}\text { Active, no restrictions } \\
\text { Femoral orthosis }\end{array}$ & Full/full & $\begin{array}{l}\text { Tibial fracture through the } \\
\text { healed pseudarthrosis } 6.4 \\
\text { months after surgery }\end{array}$ & $\begin{array}{l}\text { Closed reduction and stabilisa- } \\
\text { tion of the fracture using two } \\
\text { Prévot nails }\end{array}$ \\
\hline
\end{tabular}

The patient (case 3) treated by resection of the periosteum and proximal and distal corrective osteotomies, intramedullary nailing, and rhBMP-2 showed complete consolidation of both osteotomies and full correction of the deformity at the latest follow-up, 34 months after surgery.

After a mean follow-up of 31.0 months (10 to 48) all patients were pain-free and fully active. Four used a fullcontact knee-ankle-foot orthosis and the other walked with a femoral orthosis. Knee movements were full in all patients. Movements of the ankle were normal in three, limited in another, and one had no movement (Tables III and IV).

\section{Discussion}

The optimal treatment of CPT remains controversial..$^{2-9}$ In a multicentre review of 340 patients who underwent 1287 surgical procedures, the rate of union ranged from $28 \%$ to $75 \% .{ }^{23}$ The Ilizarov technique emerged as the best method with the highest rate of union $(75.5 \%) .{ }^{23}$ In another multicentre study, the records of 73 patients with CPT who underwent different procedures were collected from 32 hospitals in Japan. ${ }^{9}$ The authors concluded that the Ilizarov method ( $84 \%$ union) and vascularised fibular bone grafting $(74 \%$ union) were the most acceptable. ${ }^{9}$ Intramedullary fixation and autogenous bone grafting alone did not provide satisfactory results, with persistent nonunion in seven of 12 patients, as demonstrated by Kim and Weinstein. ${ }^{4}$ Conversely, Dobbs et $\mathrm{al}^{7}$ reported an initial healing rate of $86 \%$ (18 of 21 patients) after excision of the pseudarthrosis, autologous bone grafting, and intramedullary fixation. Many operations are often required. ${ }^{2,23}$ For example, 29 patients (32 cases) underwent 154 surgical procedures including bone grafting, intramedullary nailing, Ilizarov fixation and free vascularised grafting to achieve union. ${ }^{2}$

In our series, the results were promising in the four patients in whom rhBMP-2 was used with intramedullary stabilisation and external fixation. We demonstrated accelerated healing (mean 3.5 months; 3.2 to 4 ) compared to other studies. In Dobbs' series of 21 patients, the average time to initial union was 16 months after excision of the pseudarthrosis, autologous bone grafting and intramedullary fixation. ${ }^{7}$ In another study of 11 patients, in which Ilizarov fixation was used, the average time to union was 10.6 months. ${ }^{5}$ Conversely, there were a few cases of CPT that healed after three to five months without the use of BMP. ${ }^{23}$ As a result of this accelerated healing we were able to remove the Ilizarov fixator after a mean of 4.2 months (3.0 to 5.3), compared to 12.4 months in the abovementioned study. ${ }^{5}$

Two of our patients sustained a re-fracture at the initial pseudarthrosis site. This rate is comparable with that reported by Dobbs et $\mathrm{al}^{7}$ (12 of $21,57 \%$ ) and Cho et $\mathrm{al}^{24}$ (22 of 43, 52\% after Ilizarov external fixation and autogenous bone grafting). However, our smaller number of patients and shorter of follow-up prevent us from making a definitive statement about the re-fracture rate.

The use of rhBMP-2 in the treatment of CPT has been described in only one study so far. ${ }^{17}$ In that series of seven 
patients rhBMP-2 was used in combination with autogenous bone graft and the Williams intramedullary rod after resection of the pseudarthrosis. ${ }^{17}$ There was radiological union in five patients at a mean of 6.4 months (3.7 to 8.1). In our series radiological union of the pseudarthrosis was evident in all patients at a mean of 3.5 months (3.2 to 4$)$ after primary surgical treatment. The improvement in the rate of union and in time to initial healing may be attributed to the additional use of Ilizarov external fixation, perhaps reflecting the importance of mechanical compression, which can provide a better biological stimulus for healing. Post-operatively, the patients in the other rhBMP-2 study were managed in a non-weight-bearing above-knee cast with the knee in flexion for three months. ${ }^{17}$ Our patients who were treated with the Ilizarov device were allowed fullweight-bearing after surgery, and then managed with a fullweight-bearing orthosis to varying degrees after removal of the Ilizarov frame.

The use of rhBMP-7 for the treatment of CPT has been reported by Lee et $\mathrm{al}^{18}$ whereby five patients underwent osteosynthesis with use of rhBMP-7, corticocancellous allograft and intramedullary nail fixation. Four of these patients also had unilateral external fixation. Union was achieved in only one patient after 12 months, and the authors stated that one of the compounding factors that might have caused poor healing was the high degree of stiffness of the unilateral external fixators. ${ }^{18}$ Three other case reports demonstrated healing of CPT after treatment with rhBMP-7. ${ }^{19-21}$ In two of these, rhBMP-7 was used in combination with Ilizarov external fixation, leading to rapid union after three and five months, respectively. ${ }^{20,21}$ These results are in line with our findings using rhBMP-2.

In our study, there were no side effects associated with rhBMP-2 and no radiological changes in the proximal or distal tibial physes or abnormal bone growth related to its use. However, one patient developed a compartment syndrome two days post-operatively, which was thought possibly to be related to the use of rhBMP-2, as excessive swelling is reported with these drugs. ${ }^{17,25}$ In this context, Oetgen and Richards ${ }^{25}$ evaluated the use of rhBMP-2 in 81 children and found only few complications that were felt to be directly attributable to its use. They concluded that rhBMP-2 is relatively safe in young patients but because it is used in an 'off-label' fashion in children, the authors recommend a thorough discussion of the possible risk and benefits with the family beforehand. ${ }^{25}$

The limitations of our study include its retrospective nature, the small number of patients, the relatively short follow-up and the lack of randomisation. Nevertheless, our results demonstrate that treatment of CPT using rhBMP-2 combined with intramedullary stabilisation and Ilizarov external fixation may improve the rate of union and reduce the time to union. Further studies with more patients and longer follow-up are necessary.

No benefits in any form have been received or will be received from a commercial party related directly or indirectly to the subject of this article.

\section{References}

1. Vander Have KL, Hensinger RN, Caird M, Johnston C, Farley FA. Congenital pseudarthrosis of the tibia. J Am Acad Orthop Surg 2008;16:228-36.

2. Traub JA, O'Connor W, Masso PD. Congenital pseudarthrosis of the tibia: a retrospective review. J Pediatr Orthop 1999;19:735-8.

3. Minami A, Kasahima T, Iwasaki N, Kato H, Kaneda K. Vascularised fibular grafts: an experience of 102 patients. J Bone Joint Surg [Br] 2000;82-B:1022-5.

4. Kim HW, Weinstein SL. Intramedullary fixation and bone grafting for congenital pseudarthrosis of the tibia. Clin Orthop 2002;405:250-7.

5. Guidera KJ, Raney EM, Ganey T, et al. Ilizarov treatment of congenital pseudarthroses of the tibia. J Pediatr Orthop 1997;17:668-74.

6. Joseph B, Somaraju VV, Shetty SK. Management of congenital pseudarthrosis of the tibia in children under 3 years of age: effect of early surgery on union of the pseudarthrosis and growth of the limb. J Pediatr Orthop 2003;23:740-6.

7. Dobbs MB, Rich MM, Gordon JE, Szymanski DA, Schoenecker PL. Use of an intramedullary rod for treatment of congenital pseudarthrosis of the tibia: a long-term follow-up study. J Bone Joint Surg [Am] 2004;86-A:1186-97.

8. Inan M, El Rassi G, Riddle EC, Kumar SJ. Residual deformities following successful initial bone union in congenital pseudarthrosis of the tibia. J Pediatr Orthop 2006;26:393-9.

9. Ohnishi I, Sato W, Matsuyama J, et al. Treatment of congenital pseudarthrosis of the tibia: a multicenter study in Japan. J Pediatr Orthop 2005;25:219-24.

10. Sampath TK, Maliakal JC, Hauschka PV, et al. Recombinant human osteogenic protein-1 (hOP-1) induces new bone formation in vivo with a specific activity comparable with natural bovine osteogenic protein and stimulates osteoblast proliferation and differentiation in vitro. J Biol Chem 1992;267:20352-62.

11. Salkeld SL, Patron LP, Barrack RL, Cook SD. The effect of osteogenic protein-1 on the healing of segmental bone defects treated with autograft or allograft bone. $J$ Bone Joint Surg [Am] 2001;83-A:803-16.

12. Kloen P, Di Paola M, Borens 0, et al. BMP signaling components are expressed in human fracture callus. Bone 2003;33:362-71

13. Spiro AS, Beil FT, Baranowsky A, et al. BMP-7 induced ectopic bone formation and fracture healing is impaired by systemic NSAID application in C57BL/6-mice. $J$ Orthop Res 2010;28:785-91

14. Ripamonti U, Van Den Heever B, Sampath TK, et al. Complete regeneration of bone in the baboon by recombinant human osteogenic protein-1 (hOP-1, bone morphogenetic protein-7). Growth Factors 1996;13:273-89.

15. Friedlaender GE, Perry CR, Cole JD, et al. Osteogenic protein-1 (bone morphogenetic protein-7) in the treatment of tibial nonunions: a prospective, randomized clinical trial comparing rhOP-1 with fresh bone autograft. J Bone Joint Surg [Am]2001;83A(Suppl):151-8.

16. Govender S, Csimma C, Genant HK, et al; BMP-2 Evaluation in Surgery for Tibial Trauma (BESTT) Study Group. Recombinant human bone morphogenetic protein-2 for treatment of open tibial fractures: a prospective, controlled, randomized study of four hundred and fifty patients. J Bone Joint Surg [Am] 2002;84-A:2123-34.

17. Richards BS, Oetgen ME, Johnston CE. The use of rhBMP-2 for the treatment of congenital pseudarthrosis of the tibia: a case series. J Bone Joint Surg [Am] 2010;92A:177-85

18. Lee FY, Sinicropi SM, Lee FS, et al. Treatment of congenital pseudarthrosis of the tibia with recombinant human bone morphogenetic protein-7 (rhBMP-7): a report of five cases. J Bone Joint Surg [Am] 2006;88-A:627-33.

19. Fabeck L, Ghafil D, Gerroudj M, Baillon R, Delincé P. Bone morphogenetic protein 7 in the treatment of congenital pseudarthrosis of the tibia. J Bone Joint Surg $[\mathrm{Br}]$ 2006;88-B:116-18.

20. Kujala S, Vähäsarja V, Serlo W, Jalovaara P. Treatment of congenital pseudarthrosis of the tibia with native bovine BMP: a case report. Acta Orthop Belg 2008;74:132-6.

21. Anticevic D, Jelic M, Vukicevic S. Treatment of a congenital pseudarthrosis of the tibia by osteogenic protein-1 (bone morphogenetic protein-7): a case report. $J$ Pediatr Orthop B 2006;15:220-1.

22. Crawford AH. Neurofibromatosis in the pediatric patient. Orthop Clin North Am 1978;9:11-23.

23. Grill F, Bollini G, Dungl P, et al. Treatment approaches for congenital pseudarthrosis of tibia: results of the EPOS multicenter study (European Paediatric Orthopaedic Society). J Pediatr Orthop B 2000;9:75-89

24. Cho TJ, Choi IH, Lee SM, et al. Refracture after Ilizarov osteosynthesis in atrophictype congenital pseudarthrosis of the tibia. J Bone Joint Surg [Br] 2008;90-B:488-93.

25. Oetgen ME, Richards BS. Complications associated with the use of bone morphogenetic protein in pediatric patients. J Pediatr Orthop 2010;30:192-8. 